\title{
Prevalence, detection, and management of cardiovascular risk factors in different ethnic groups in south London
}

Francesco P Cappuccio, Derek G Cook, Richard W Atkinson, Pasquale Strazzullo

\begin{abstract}
Objective-To assess the prevalence of cardiovascular risk factors and their level of detection and management in three ethnic groups.

Design-Population based survey during 1994 to 1996.

Setting-Former Wandsworth Health Authority in South London.

Subjects-1578 men and women, aged 40 to 59 years; 524 white, 549 of African descent, and 505 of South Asian origin.

Main outcome measures-Age adjusted prevalence of hypertension, diabetes, obesity, raised serum cholesterol, and smoking.
\end{abstract}

Results-Ethnic minorities of both sexes had raised prevalence rates of hypertension and diabetes compared to white people. Age and sex standardised prevalence ratios for hypertension were 2.6 (95\% confidence interval 2.1 to 3.2 ) in people of African descent and $1.8(1.4$ to 2.3$)$ in those of South Asian origin. For diabetes, the ratios were $2.7(1.8$ to 4.0$)$ in people of African descent and $3.8(2.6$ to 5.6$)$ in those of South Asian origin. Hypertension and diabetes were equally common among Caribbeans and West Africans and among South Asian Hindus and Muslims. Prevalence of severe obesity was high overall, but particularly among women of African descent $(40 \%(35 \%$ to $45 \%))$. In contrast, raised serum cholesterol and smoking rates were higher among white people. Of hypertensives, $49 \%$ (216 of 442 ) had adequate blood pressure control. Overall, $18 \%$ ( 80 of 442 ) of hypertensives and $33 \%$ (62 of 188) of diabetics were undetected before our survey. Hypertensive subjects of African descent appeared more likely to have been detected $(p=0.034)$ but less likely to be adequately managed $(\mathrm{p}=0.085)$.

Conclusions-Hypertension and diabetes are raised two- to threefold in South Asians, Caribbeans, and West Africans in Britain. Detection, management, and control of hypertension has improved, but there are still differences between ethnic groups. Obesity is above the Health of the Nation targets in all ethnic groups, particularly in women of African descent. Preventive and treatment strategies for different ethnic groups in Britain need to consider both cultural differences and underlying susceptibility to different vascular diseases.

(Heart 1997;78:555-563)

Keywords: cardiovascular risk factors; hypertension; diabetes; obesity; ethnic group

Cardiovascular disease is the most common and yet one of the most preventable causes of death. Moreover the risk of premature disease varies by ethnic group. Relative to white subjects, Afro-Caribbeans and people of African descent have high incidence of stroke ${ }^{1}$ and end stage renal failure, ${ }^{2}{ }^{3}$ whereas coronary heart disease is less common. On the other hand, South Asians (from the Indian subcontinent and from East Africa) have a higher incidence of coronary heart disease. ${ }^{1}$ Although a different genetic make up might, in part, explain such differences, environmental and modifiable factors relating to diet and lifestyle play an important role.

In 1991 the British government set new targets for the health of the nation, with coronary heart disease and stroke as key areas. ${ }^{5}$ The objectives are to reduce the levels of ill health and death caused by coronary heart disease and stroke, and the risk factors associated with them. Different strategies were set up, for instance to reduce blood cholesterol concentrations and smoking rates, with the major focus on the population, mostly white, of England and Wales. The Health survey for England ${ }^{6}$ was set up to monitor trends in the risk factor levels. However, no particular emphasis was given to ethnic minorities and few comparative data are available.

Just over three million people in England and Wales belong to ethnic minorities; these groups are concentrated in and around inner cities. ${ }^{7}$ Morbidity and mortality from vascular disease and use of health care resources are likely to be high in such areas, and the Health of the Nation strategies may not apply to these groups, for which more tailored preventive strategies may be needed.

We carried out a population based survey in South London to estimate the prevalence of the major cardiovascular risk factors in both men and women of different ethnic background, and to provide data on current detection rates and management of hypertension and diabetes.

\section{Methods}

POPULATION SAMPLING

The general practice sample was drawn from within the former Wandsworth Health Author- 
ity (WHA) in South London. It has a population of approximately 190000 . About $25 \%$ of their residents were born outside the United Kingdom; $12 \%$ are of African descent and $6 \%$ of Indian or Pakistani origin. There were 65 general practices in the WHA. They varied from single handed general practitioners to group practices and fund holding ones. The distribution of the population of different ethnic background is not evenly distributed across practices and areas of the district. ${ }^{7}$ For instance, the majority of Caribbeans live in the Wandsworth-Clapham-Battersea area and in Streatham; West Africans are mostly concentrated in Balham, Mitcham and Streatham, and South Asian communities live predominantly in Balham, Tooting, Mitcham, and Wandsworth. As a result, a sampling procedure aimed at achieving a "random" sample of each ethnic group of "equal" size needs to consider these demographic characteristics.

The 65 practices were surveyed to assess their suitability and willingness to participate. Practices were considered unsuitable if they did not have a computerised age and sex register, did not have a sufficient ethnic minority population registered, or were unwilling to participate. Of the 25 practices thought suitable, nine were selected to provide a balanced geographical and ethnic mix. One was fund holding, two were run by single handed practitioners, and six were health centres with four to six practitioners. The practices and their surgeries were located in Balham, Battersea, Clapham, Mitcham, Streatham, Tooting, and Wandsworth. From each practice, a list was obtained of all men and women aged 40 to 59 years registered with the practice and resident within the study area. Participants with Chinese, Japanese, or Vietnamese names were excluded, as were patients with cancer, severe disability, severe psychiatric disturbance, or pregnant women.

In order to obtain an approximately equal number of participants in each sex and ethnic specific stratum, all names suggestive of a South Asian origin and of West African origin were selected. In addition patients of AfroCaribbean origin were identified by a combination of name searching and contact with the general practitioners and the receptionist or practice nurse at the surgery. In a pilot study carried out in 1992, name searching identified $80 \%$ of white subjects, $94 \%$ of South Asians and West Africans, but only $51 \%$ of Caribbeans. This precision improved when contact with practice staff was used. The results of the likely response rate of the pilot study were used in the main study to draw a proportional random sample of white patients so as to yield a number of participants approximately equal to the other ethnic groups.

Fieldwork was undertaken from March 1994 to July 1996. Ethnic group was recorded at the time of interview, based on the answers to a combination of questions including place and country of birth, language, religion, history of migration, and parental country of birth. ${ }^{8}$ In all, 3606 invitations were sent on the headed paper of each individual practice and cosigned by a general practitioner and the study coordinator. Translations in four main Asian languages were also provided. A first reminder and, if necessary, a second were sent by recorded delivery. Whenever possible the invitations were followed up by a telephone call. Of the letters sent, $952(26 \%)$ were returned by the Post Office. Of the 2654 men and women who received invitations, 479 (18\%) never responded, $480(18 \%)$ refused to participate, and 1695 (64\%) took part. To those who refused to take part, a questionnaire was sent to establish basic demographic characteristics and medical history of vascular disease. The response rate was $76 \%$ (363 of 480).

Ten per cent of the addressees (96 of 952) whose letters were returned by the Post Office and $56 \%$ (269 of 479) of those who never responded and whose letters were not returned appeared on the electoral register. It seems likely that a substantial proportion of those not responding were not currently living at the address given and that, on balance, our response rate is likely to represent an underestimate of the "true" response rate. Seven records were removed because of incomplete examination, so that a total sample of 1688 was available; 110 participants were then removed from the present analysis since they did not belong to one of the three ethnic groups under study. The final sample size was 1578 .

\section{SAMPLE SIZE CONSIDERATIONS}

Sample size estimates were carried out considering both power and precision. For example, the expected prevalence of diabetes in white men was 5\% and in South Asian men $15 \% .^{9} \mathrm{At}$ least 250 participants in each group were therefore needed to have a power of $90 \%$ to detect that difference in prevalence at the $1 \%$ level of significance with a standard error of $\pm 2 \%$ for the prevalence point estimates. A target sample size of at least 1500 was chosen (approximately 250 in each sex and ethnic stratum).

ETHICS

The study protocol was approved by the local ethics committee. All participants gave their informed consent to participate.

\section{PROCEDURES}

Participants attended a dedicated screening unit at St George's Hospital between 0800 and 1200, after an overnight fast. Their invitation letters asked them to refrain from smoking and from taking vigorous exercise for at least one hour before the visit and to bring all drugs with them for checking.

\section{Physical measurements}

Height was measured without shoes to the nearest $\mathrm{cm}$ using a ruler attached to the wall; weight was measured to the nearest $0.1 \mathrm{~kg}$ on an electronic scale with the subject wearing light indoor clothing and no shoes. The body mass index (BMI) was calculated as weight $(\mathrm{kg})$ divided by the square of the height $(\mathrm{m})$. After the subject had been resting for at least 10 
Hypertension
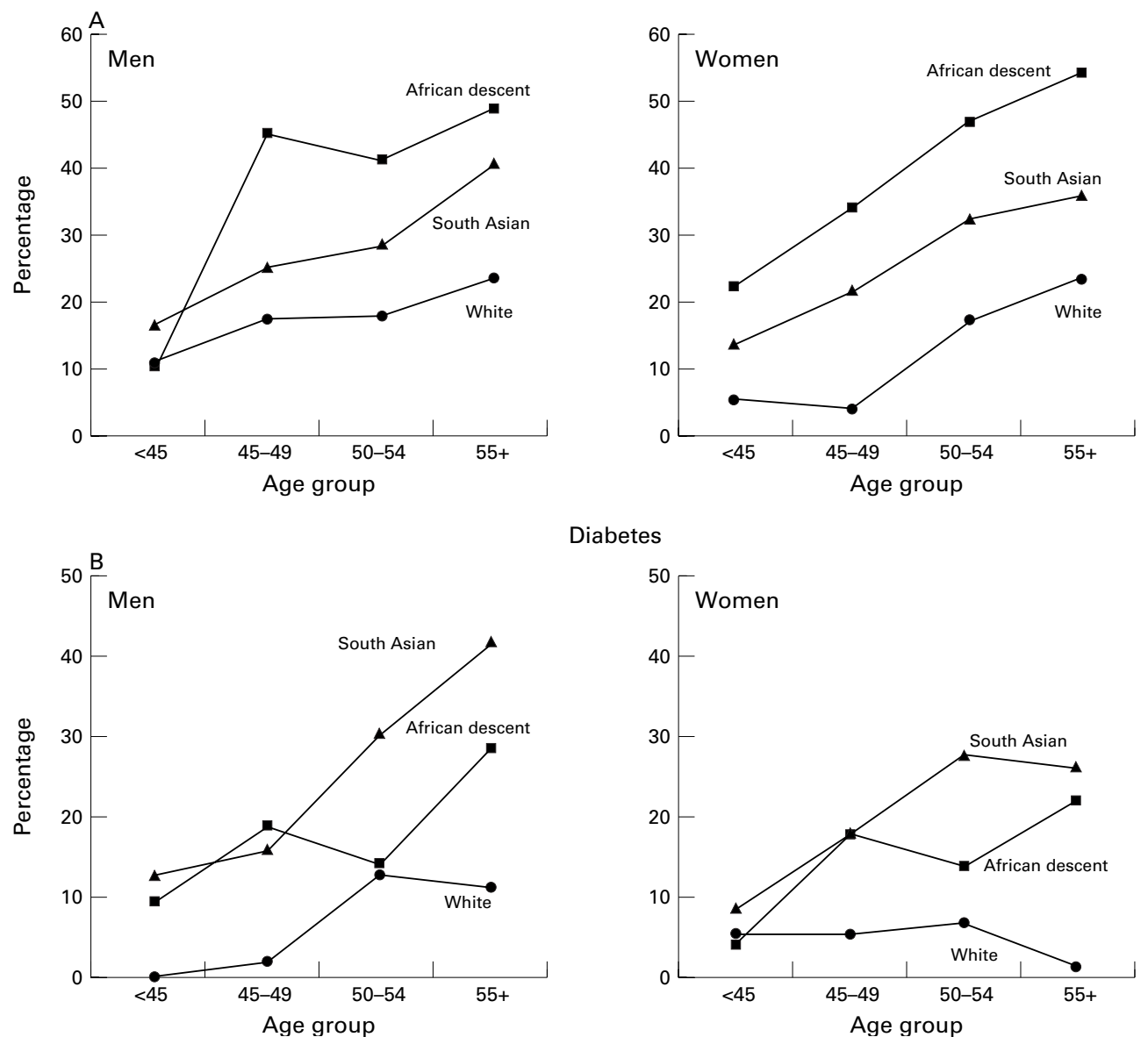

Diabetes

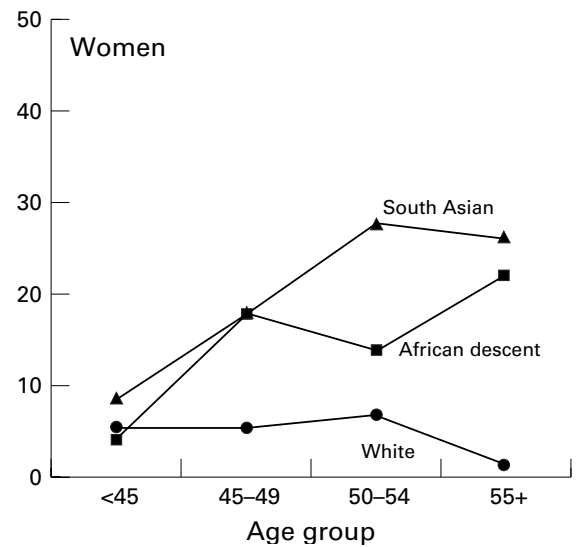

Figure 1 Prevalence (\%) of hypertension $(A)$ and diabetes (B) by ethnic group and age category in men and women. The Wandsworth heart and stroke study, 1994-96.

minutes in the supine position, systolic and diastolic blood pressures were taken three times, with two minute intervals between measurements, using an automatic ultrasound sphygmomanometer (Arteriosonde, Roche Products, Welwyn Garden City, UK) ${ }^{10}$ by nurses who had attended training sessions for standardisation of the procedure. Blood pressure was measured in the left arm using cuffs of a size appropriate to the arm circumference, according to the recommendations of the British Hypertension Society. ${ }^{11}$ The average of the last two readings was used for the analyses.

A urine Diastix (BM-Test 8; Boeringher Mannheim, Mannheim, Germany) was used to check for the presence of glycosuria. Fasting venous blood was taken in the seated position without stasis.

\section{Oral glucose tolerance test}

After these measurements and procedures, participants not known to be diabetic and without glycosuria (defined as urinary glucose $\geqslant 5.5 \mathrm{mmol} / \mathrm{l}$ ) drank $75 \mathrm{~g}$ of dextrose monohydrate (Glucose BMS, Bio-Medical Services, York, UK) dissolved in $250 \mathrm{ml}$ of tap water over five minutes and a second venous blood sample was taken two hours later ( \pm five minutes).

Table 1 Age adjusted prevalence rates of major risk factors for cardiovascular disease in men by ethnic group

\begin{tabular}{|c|c|c|c|c|c|c|c|c|c|}
\hline \multirow[b]{2}{*}{ Risk factor } & \multicolumn{3}{|c|}{ White people } & \multicolumn{3}{|c|}{ African descent } & \multicolumn{3}{|c|}{ South Asian origin } \\
\hline & $n$ & $\%$ & $95 \% C I$ & $n$ & $\%$ & $95 \% C I$ & $n$ & $\%$ & $95 \% C I$ \\
\hline Hypertension & 233 & 17.8 & $13.4,23.6$ & 208 & 36.8 & $30.3,43.5$ & 254 & 27.9 & $22.7,33.9$ \\
\hline Diabetes & 181 & 6.7 & $3.5,11.3$ & 157 & 17.9 & $12.4,24.7$ & 211 & 25.4 & $20.0,32.0$ \\
\hline Obesity (BMI >27) & 232 & 30.5 & $25.0,37.0$ & 208 & 38.7 & $32.6,45.9$ & 253 & 24.2 & $19.1,29.9$ \\
\hline Obesity $(\mathrm{BMI}>30)$ & 232 & 14.8 & $10.5,19.9$ & 208 & 14.8 & $10.5,20.5$ & 253 & 8.4 & $5.3,12.4$ \\
\hline Cholesterol $>5.2 \mathrm{mmol} / 1$ & 226 & 77.8 & $72.6,83.1$ & 197 & 58.0 & $51.2,64.9$ & 240 & 67.9 & $62.2,73.8$ \\
\hline Cholesterol $>6.5 \mathrm{mmol} / 1$ & 226 & 37.3 & $31.1,43.8$ & 197 & 15.5 & $11.1,21.6$ & 240 & 22.4 & $17.5,28.3$ \\
\hline Smoking & 231 & 39.6 & $33.4,46.0$ & 205 & 18.6 & $13.6,24.5$ & 249 & 25.2 & $20.2,31.2$ \\
\hline
\end{tabular}

Results are numbers of observations (n), mean point estimate (\%), and 95\% confidence intervals (CI).

Hypertension is defined as systolic blood pressure $\geqslant 160 \mathrm{and} /$ or diastolic $\geqslant 95 \mathrm{~mm} \mathrm{Hg}$ or on drug treatment.

Diabetes is defined according to WHO criteria: fasting venous plasma blood glucose $\geqslant 7.8 \mathrm{mmol} / \mathrm{l}$ or a venous plasma glucose $2 \mathrm{~h}$ after oral loading $>11.1 \mathrm{mmol} / 1$, or both.

BMI, body mass index $\left(\mathrm{kg} / \mathrm{m}^{2}\right)$. 
Table 2 Age adjusted prevalence rates of major risk factors for cardiovascular disease in women by ethnic group

\begin{tabular}{|c|c|c|c|c|c|c|c|c|c|}
\hline \multirow[b]{2}{*}{ Risk factor } & \multicolumn{3}{|c|}{ White people } & \multicolumn{3}{|c|}{ African descent } & \multicolumn{3}{|c|}{ South Asian origin } \\
\hline & $n$ & $\%$ & $95 \% C I$ & $n$ & $\%$ & $95 \% C I$ & $n$ & $\%$ & $95 \% C I$ \\
\hline Hypertension & 291 & 12.7 & $9.2,17.1$ & 341 & 39.8 & $34.9,45.3$ & 251 & 26.1 & $20.8,31.8$ \\
\hline Diabetes & 210 & 5.2 & $2.7,9.2$ & 245 & 14.9 & $11.0,20.2$ & 191 & 20.5 & $15.1,26.8$ \\
\hline Obesity (BMI >27) & 291 & 34.3 & $29.1,40.1$ & 339 & 67.9 & $63.0,72.8$ & 250 & 48.0 & $42.0,54.4$ \\
\hline Obesity $(\mathrm{BMI}>30)$ & 291 & 18.8 & $14.7,23.9$ & 339 & 39.8 & $34.8,45.3$ & 250 & 19.7 & $15.0,25.1$ \\
\hline Cholesterol $>5.2 \mathrm{mmol} / 1$ & 275 & 78.1 & $73.4,82.9$ & 303 & 60.6 & $55.0,65.9$ & 229 & 67.6 & $61.8,73.7$ \\
\hline Cholesterol $>6.5 \mathrm{mmol} / 1$ & 275 & 36.3 & $30.9,42.4$ & 303 & 21.9 & $17.4,26.9$ & 229 & 18.6 & $14.1,24.4$ \\
\hline Smoking & 284 & 33.3 & $27.9,38.9$ & 333 & 9.2 & $6.5,13.0$ & 241 & 2.9 & $1.2,5.9$ \\
\hline
\end{tabular}

Results are numbers of observations (n), mean point estimate (\%), and 95\% confidence intervals (CI).

Hypertension is defined as systolic blood pressure $\geqslant 160$ and/or diastolic $\geqslant 95 \mathrm{~mm} \mathrm{Hg}$ or on drug treatment.

Diabetes is defined according to WHO criteria: fasting venous plasma blood glucose $\geqslant 7.8 \mathrm{mmol} / 1$ or a venous plasma glucose $2 \mathrm{~h}$ after oral loading $>11.1 \mathrm{mmol} / 1$, or both.

BMI, body mass index $\left(\mathrm{kg} / \mathrm{m}^{2}\right)$.

\section{Blood tests}

Blood samples were processed within two to three hours. Fluoridated plasma was sent to the laboratory for immediate determination of glucose by the glucose oxidase method. Blood for lipids was collected in plain Vacutainer tubes, left to clot, spun at $1500 \times g$ for 10 minutes at $4^{\circ} \mathrm{C}$ and serum separated and stored at $-40^{\circ} \mathrm{C}$ until assayed. Aliquots were shipped in dry ice to the University of Naples for biochemical analysis. Serum cholesterol was measured by automated methods (Cobas Mira, Roche, Milan, Italy). The coefficient of variation (CV) between assays for cholesterol was $1.8 \%$. In addition, cholesterol determination underwent an external quality control from the World Health Organisation Lipid Reference Centre in Prague.

\section{Questionnaire}

A questionnaire was administered which included place and country of birth, language, religion, history of migration, parental place and country of birth, family and personal medical history, and drug treatment. Current and past smoking were recorded.
DEFINITION OF RISK FACTORS

Hypertension was defined as systolic blood pressure $\geqslant 160 \mathrm{~mm} \mathrm{Hg}$ and/or diastolic blood pressure $\geqslant 95 \mathrm{~mm} \mathrm{Hg}^{12}$ or being on pharmacological treatment for hypertension. The Arteriosonde has been validated as providing blood pressures directly comparable with standard mercury sphygmomanometers. ${ }^{10}$ Diabetes was defined according to the WHO criteria for epidemiological investigations by using venous plasma, ${ }^{13}$ that is, a fasting glucose concentration of $\geqslant 7.8 \mathrm{mmol} / \mathrm{l}$, or a glucose concentration two hours after oral loading of $\geqslant 11.1 \mathrm{mmol} / 1$, or both. Subjects who at the time of the study had already been diagnosed as diabetic ("known diabetic") and those with Diastix glycosuria at the time of screening were assumed to be diabetic. Obesity was defined as a BMI of $>27 \mathrm{~kg} / \mathrm{m}^{2}$ (moderate) or $>30 \mathrm{~kg} / \mathrm{m}^{2}$ (severe) in both men and women. Raised serum cholesterol was considered at two different cut off points (>5.2 and > $>.5 \mathrm{mmol} / \mathrm{l}$ ). Subjects were classified as non-smokers (if they had never smoked cigarettes, cigars, or pipe), ex-smokers (if they had smoked cigarettes in the past and were not regular cigar or pipe smokers at the present), and current smokers

Table 3 Age adjusted prevalence rates of major risk factors for cardiovascular disease by sex and ethnic subgroups

\begin{tabular}{|c|c|c|c|c|c|c|c|c|}
\hline \multirow[b]{3}{*}{ Risk factor } & \multicolumn{4}{|l|}{ Men } & \multicolumn{4}{|c|}{ Women } \\
\hline & \multicolumn{2}{|c|}{ Caribbeans } & \multicolumn{2}{|c|}{ West Africans } & \multicolumn{2}{|c|}{ Caribbeans } & \multicolumn{2}{|c|}{ West Africans } \\
\hline & $n$ & $\begin{array}{l}\text { \% } \\
(95 \% C I)\end{array}$ & $n$ & $\begin{array}{l}\text { \% } \\
(95 \% C I)\end{array}$ & $n$ & $\begin{array}{l}\text { \% } \\
(95 \% C I)\end{array}$ & $n$ & $\begin{array}{l}\text { \% } \\
(95 \% C I)\end{array}$ \\
\hline Hypertension & 118 & $\begin{array}{l}31.2 \\
23.6,40.5\end{array}$ & 84 & $\begin{array}{l}39.8 \\
29.6,50.5\end{array}$ & 219 & $\begin{array}{l}\mathbf{4 0 . 3} \\
34.0,47.0\end{array}$ & 110 & $\begin{array}{l}\text { 40.0 } \\
31.4,49.8\end{array}$ \\
\hline Diabetes & 88 & $\begin{array}{l}\mathbf{1 3 . 3} \\
7.4,22.6\end{array}$ & 64 & $\begin{array}{l}\mathbf{2 0 . 9} \\
11.7,32.2\end{array}$ & 153 & $\begin{array}{l}\mathbf{1 8 . 7} \\
13.3,26.1\end{array}$ & 83 & $\begin{array}{l}\mathbf{1 0 . 5} \\
5.2,19.6\end{array}$ \\
\hline Obesity (BMI >27) & 118 & $\begin{array}{l}\mathbf{3 4 . 2} \\
25.9,43.2\end{array}$ & 84 & $\begin{array}{l}40.5 \\
30.7,51.7\end{array}$ & 218 & $\begin{array}{l}\mathbf{6 5 . 5} \\
59.5,71.9\end{array}$ & 83 & $\begin{array}{l}\text { 72.0 } \\
64.4,80.6\end{array}$ \\
\hline Obesity (BMI >30) & 118 & $\begin{array}{l}\mathbf{1 2 . 2} \\
6.8,19.1\end{array}$ & 84 & $\begin{array}{l}13.7 \\
7.8,23.6\end{array}$ & 218 & $\begin{array}{l}39.9 \\
33.7,46.7\end{array}$ & 109 & $\begin{array}{l}\mathbf{4 0 . 3} \\
31.7,50.2\end{array}$ \\
\hline Cholesterol $>5.2 \mathrm{mmol} / 1$ & 109 & $\begin{array}{l}\mathbf{5 5 . 1} \\
46.1,64.6\end{array}$ & 82 & $\begin{array}{l}\mathbf{5 8 . 3} \\
48.4,69.3\end{array}$ & 189 & $\begin{array}{l}\mathbf{5 9 . 8} \\
53.0,66.8\end{array}$ & 102 & $\begin{array}{l}\mathbf{5 6 . 2} \\
46.7,65.7\end{array}$ \\
\hline Cholesterol $>6.5 \mathrm{mmol} / \mathrm{l}$ & 109 & $\begin{array}{l}\mathbf{2 0 . 5} \\
13.4,28.9\end{array}$ & 82 & $\begin{array}{l}\mathbf{1 2 . 4} \\
6.2,21.3\end{array}$ & 189 & $\begin{array}{l}\mathbf{2 0 . 9} \\
15.3,27.1\end{array}$ & 102 & $\begin{array}{l}24.3 \\
16.9,34.0\end{array}$ \\
\hline Smoking & 118 & $\begin{array}{l}\mathbf{2 9 . 0} \\
21.2,37.9\end{array}$ & 81 & $\begin{array}{l}4.1 \\
0.8,10.4\end{array}$ & 215 & $\begin{array}{l}\mathbf{1 2 . 6} \\
8.5,17.7\end{array}$ & 106 & $\begin{array}{l}3.2 \\
0.6,8.0\end{array}$ \\
\hline
\end{tabular}

Results are numbers of observations (n), mean point estimate (\%), and $95 \%$ confidence intervals (CI).

Hypertension is defined as systolic blood pressure $\geqslant 160$ and/or diastolic $\geqslant 95 \mathrm{~mm} \mathrm{Hg}$ or on drug treatment.

Diabetes is defined according to WHO criteria: fasting venous plasma blood glucose $\geqslant 7.8 \mathrm{mmol} / \mathrm{l}$ or a venous plasma glucose $2 \mathrm{~h}$ after oral loading $>11.1 \mathrm{mmol} / \mathrm{l}$, or both. BMI, body mass index $\left(\mathrm{kg} / \mathrm{m}^{2}\right)$. 
(if they were currently smoking on a regular daily basis one or more cigarettes, cigars, or pipe per day).

\section{STATISTICAL ANALYSIS}

Data analysis was carried out using the SAS system (SAS Institute, Cary, North Carolina, USA). Prevalence rates were age standardised with the direct method, using five year age bands with equal numbers in each band as a standard population. ${ }^{14}$ Exact confidence intervals for prevalence rates were calculated from the inverse incomplete $\beta$ distribution. Age adjusted prevalence ratios were calculated using the Mantel-Haenszel method and relative odds by multiple logistic regression.

\section{Results}

CHARACTERISTICS OF THE STUDY POPULATION.

By design the three ethnic groups were of similar sample size (524 white people, 549 of African descent, and 505 of South Asian origin), with comparable numbers of men and women. The South Asian group was slightly younger (49.4 (5.9) years; mean (SD)) and the group of African descent slightly older (51.1 (5.8) years) than the white group (49.8 (5.6) years). Women tended to be younger than men in all three groups. Among the group of African descent, $62 \%$ were born in the Caribbean and $36 \%$ in West Africa. Of the South Asians, 39\% spoke Gujarati as their first language, 13\% Urdu, 10\% Bengali, 10\% English, 6\% Punjabi, $3 \%$ Hindi, and $19 \%$ other. The commonest religions were Hinduism (50\%) and Islam $(37 \%)$. The majority $(64 \%)$ were born in the Indian subcontinent, $28 \%$ in East Africa, and $3 \%$ in the West Indies.

PREVALENCE OF RISK FACTORS BY SEX AND AGE GROUPS

The prevalence of hypertension increased with age in each ethnic group and in both men and women (fig 1A). However, it was higher in

Table 3 continued

\begin{tabular}{|c|c|c|c|c|c|c|c|}
\hline \multicolumn{4}{|c|}{ Men } & \multicolumn{4}{|c|}{ Women } \\
\hline \multicolumn{2}{|c|}{ Hindus } & \multicolumn{2}{|c|}{ Muslims } & \multicolumn{2}{|c|}{ Hindus } & \multicolumn{2}{|c|}{ Muslims } \\
\hline$n$ & $\begin{array}{l}\% \\
(95 \% C I)\end{array}$ & $n$ & $\begin{array}{l}\text { \% } \\
(95 \% C I)\end{array}$ & $n$ & $\begin{array}{l}\% \\
(95 \% C I)\end{array}$ & $n$ & $\begin{array}{l}\% \\
(95 \% C I)\end{array}$ \\
\hline 123 & $\begin{array}{l}25.8 \\
18.8,34.7\end{array}$ & 95 & $\begin{array}{l}23.5 \\
15.5,32.9\end{array}$ & 127 & $\begin{array}{l}\mathbf{2 6 . 0} \\
18.9,34.5\end{array}$ & 93 & $\begin{array}{l}\mathbf{2 8 . 6} \\
20.5,39.4\end{array}$ \\
\hline 107 & $\begin{array}{l}\mathbf{2 6 . 3} \\
18.5,35.6\end{array}$ & 77 & $\begin{array}{l}23.9 \\
14.9,34.4\end{array}$ & 97 & $\begin{array}{l}\mathbf{1 8 . 8} \\
11.6,27.7\end{array}$ & 70 & $\begin{array}{l}\mathbf{2 1 . 7} \\
12.9,32.9\end{array}$ \\
\hline 123 & $\begin{array}{l}21.1 \\
14.5,29.4\end{array}$ & 94 & $\begin{array}{l}26.2 \\
18.4,36.7\end{array}$ & 126 & $\begin{array}{l}\mathbf{4 2 . 1} \\
33.9,51.2\end{array}$ & 93 & $\begin{array}{l}\mathbf{5 4 . 7} \\
45.2,65.2\end{array}$ \\
\hline 123 & $\begin{array}{l}\mathbf{6 . 6} \\
2.9,12.4\end{array}$ & 94 & $\begin{array}{l}8.9 \\
3.8,16.1\end{array}$ & 126 & $\begin{array}{l}\mathbf{1 5 . 6} \\
10.1,23.4\end{array}$ & 93 & $\begin{array}{l}\mathbf{2 4 . 3} \\
16.7,34.8\end{array}$ \\
\hline 117 & $\begin{array}{l}\mathbf{6 6 . 0} \\
57.6,74.3\end{array}$ & 87 & $\begin{array}{l}\mathbf{6 9 . 6} \\
61.0,79.5\end{array}$ & 113 & $\begin{array}{l}\mathbf{6 7 . 8} \\
59.9,76.6\end{array}$ & 87 & $\begin{array}{l}\mathbf{6 7 . 3} \\
58.5,77.4\end{array}$ \\
\hline 117 & $\begin{array}{l}\mathbf{2 0 . 3} \\
13.9,29.0\end{array}$ & 87 & $\begin{array}{l}\mathbf{2 3 . 2} \\
15.0,33.2\end{array}$ & 113 & $\begin{array}{l}\mathbf{2 0 . 5} \\
13.6,29.0\end{array}$ & 87 & $\begin{array}{l}\mathbf{1 2 . 2} \\
6.6,21.5\end{array}$ \\
\hline 121 & $\begin{array}{l}\mathbf{1 8 . 5} \\
12.0,26.2\end{array}$ & 92 & $\begin{array}{l}\mathbf{3 0 . 0} \\
21.8,40.9\end{array}$ & 124 & $1.0^{\star}$ & 87 & $\begin{array}{l}\mathbf{2 . 9} \\
0.7,9.7\end{array}$ \\
\hline
\end{tabular}




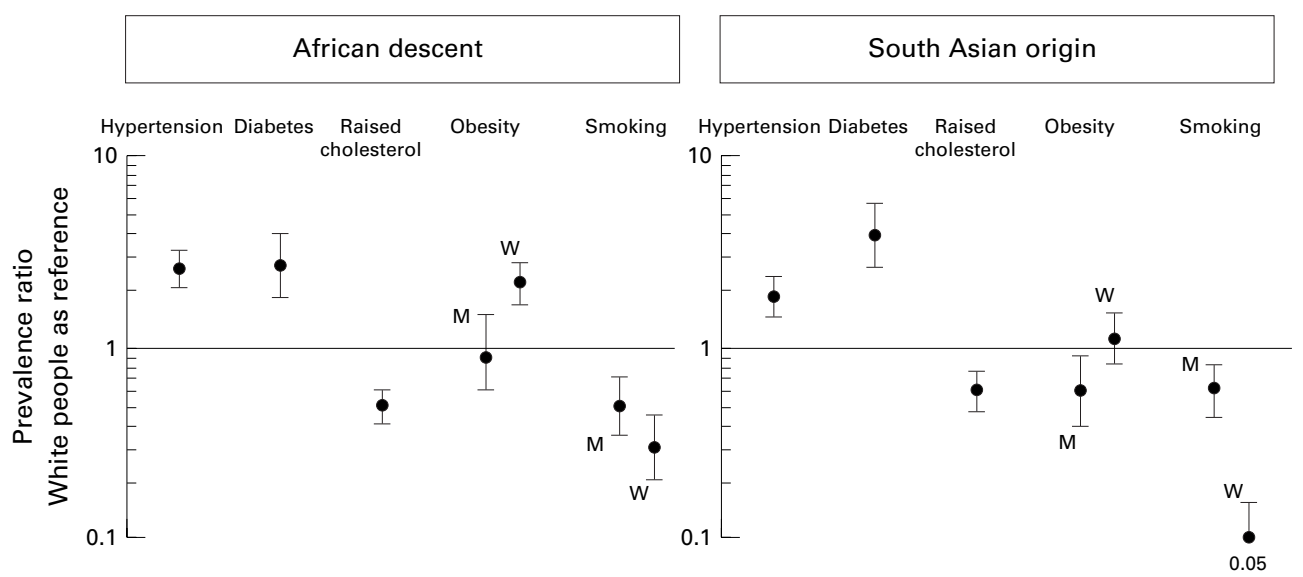

Figure 2 Prevalence ratios (and 95\% confidence intervals) for hypertension, diabetes, and raised cholesterol by ethnic group adjusted for age and sex. Those for obesity and smoking are age adjusted in men (M) and women (W) separately. The white group is taken as the reference population.

remained statistically significant after adjustment for sex, age, and general practice $(p=0.034)$. Indeed, when allowing for these potentially confounding variables, the risk of the hypertension being undetected was highest among the South Asians (odds ratio 2.34; $95 \%$ confidence interval 1.22 to $4.47 v$ people of African descent). The proportion of hypertensives inadequately treated tended to be higher among people of African descent $\left(\chi_{2}^{2}=12.7\right.$; $\mathrm{p}<0.002$ ) (fig 3). This ethnic difference was of borderline statistical significance after adjustment for sex, age, and general practice $(p=0.085)$. Thus hypertensive subjects of African descent were more likely to have been diagnosed but less likely to be adequately managed.

Over a third of people with diabetes (69 of 188) were receiving drug treatment. However, the proportion of those on drug treatment varied across ethnic groups (African descent 49\%, South Asians 30\%, white people 25\%, $\left.\chi_{2}^{2}=7.4, p=0.025\right)$. Moreover, one third of diabetics (62 of 188) were unaware of their condition and were diagnosed at the time of the survey. The detection of new cases tended to vary across ethnic groups (white people $54 \%$, South Asians 33\%, African descent 26\%). However, these differences were not statistically significant after adjustment for sex, age, and general practice $(\mathrm{p}=0.16)$.

CHARACTERISTICS OF NON-ATTENDERS

Within each ethnic group, non-attenders had similar prevalence rates of reported hypertension and diabetes to attenders (table 4). Overall the prevalence of past history of ischaemic heart disease and stroke was similar in non-attenders and attenders $(7 \% v 6 \%)$.

\section{Discussion}

In the past 20 years several surveys have been carried out to establish the prevalence of risk factors for cardiovascular disease in different ethnic groups in England and Wales. ${ }^{9}{ }^{15-22}$ Some were entirely ${ }^{1516}$ or in part ${ }^{9}$ of working populations, some studied mainly South Asian groups $^{182021}$ or Afro-Caribbeans, ${ }^{17}{ }^{22}$ some focused on diabetes only. ${ }^{18-22}$
Our present study has some advantages. It is population based, thus avoiding the "healthy worker" effect of surveys carried out in working populations. Given that ethnic minorities in Britain (in particular Caribbeans and Bangladeshis) are less likely to be in full time regular employment, selection bias is likely. We used highly standardised methodologies for the assessment of risk factors across different ethnic groups, thus avoiding systematic bias in comparisons between groups. We included men and women in each ethnic group so that systematic analyses of sex differences in risk could be performed. We examined coresident ethnic population samples in a geographically defined area so as to minimise variations in some environmental exposures and in factors influencing access to health care facilities, such as proximity factors. It is the first survey in the United Kingdom to include a large subsample of West African men and women, allowing useful comparisons between people of African ancestry born in different parts of the world and settled in the same area of London. It explores for the first time the level of detection, management, and control of hypertension and diabetes by ethnic group. This is of particular interest since it is the first survey on ethnic minorities carried out after the Health of the Nation strategy was launched, and primary and secondary care initiatives were implemented to increase the detection rates and improve the quality of management and effectiveness of control of hypertension and diabetes in England and Wales.

\section{HYPERTENSION}

The definition we employed is the same as that adopted in several similar surveys, ${ }^{19}{ }^{22-24}$ in the Health of the Nation, ${ }^{5}$ and in the Health survey for England, ${ }^{625}$ so direct comparison is appropriate. Nearly half the people of African descent in the age range 40 to 59 years have raised blood pressure requiring drug treatment. It is not surprising to find a high prevalence of hypertension in people of African descent ${ }^{22}{ }^{24}$ and it is likely that these levels contribute to the high incidence of stroke ${ }^{1}$ and end 


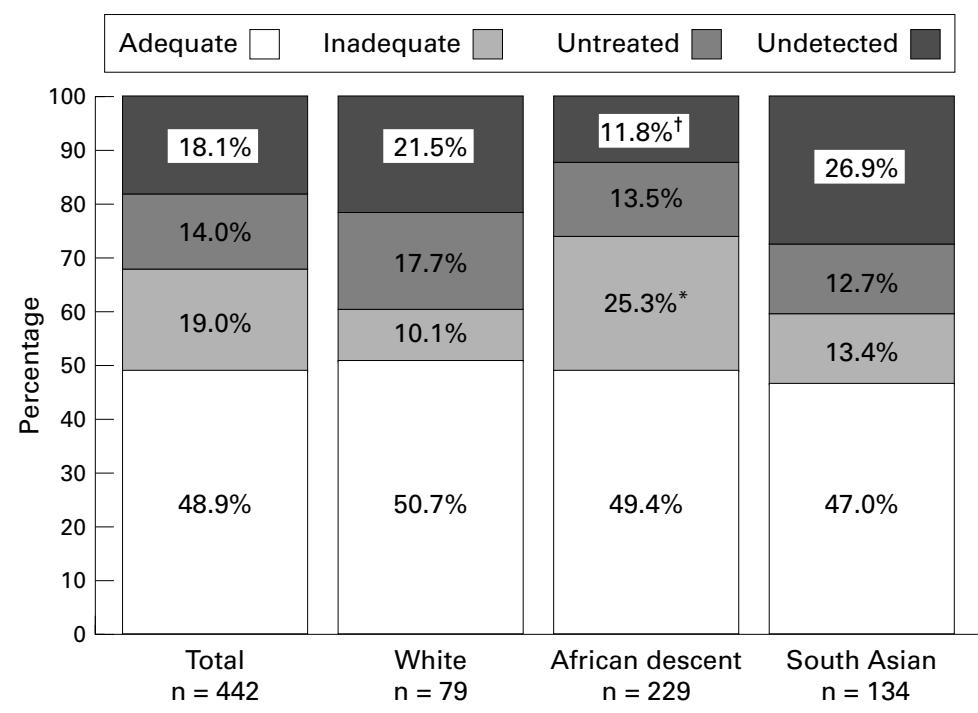

Figure 3 Levels of detection, management, and control of hypertension in the community as a whole (total) and in each ethnic group separately. The numbers indicate the proportion (\%) of participants with hypertension (blood pressure $\geqslant 160$ and/or $95 \mathrm{~mm} \mathrm{Hg}$ or on drug treatment) (1) who were on treatment and whose blood pressure was below 160 and/or $95 \mathrm{~mm} \mathrm{Hg}$ (adequate); (2) who were on treatment and whose blood pressure was $\geqslant 160$ and/or $95 \mathrm{~mm} \mathrm{Hg}$ (inadequate); (3) who were known hypertensives and on no drug treatment (untreated); (4) who had never been told they had hypertension before the screening (undetected). ${ }^{\star} p<0.002,+p=0.001$ by $\chi^{2}$ statistics when comparing the three ethnic groups.

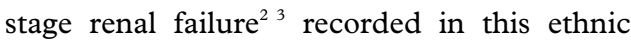
group in England and Wales.

The "rule of halves" predicts that only about $12.5 \%$ of the hypertensive population receives adequate blood pressure control. ${ }^{23}{ }^{26}$ Our findings indicate an improvement on the rules of halves in agreement with the results of the Health survey for England. ${ }^{25}$ In our locality, just under half of the hypertensive population is detected and has adequate blood pressure control, and this is true in each ethnic group. However, we still found that about a quarter of the hypertensives of African descent had not been detected or treated in the community, and about a quarter of those detected were not achieving adequate blood pressure control. This may have important implications as the risk of stroke is related to the quality of control of blood pressure by treatment, ${ }^{27}$ particularly in populations of African descent.

Recent studies in populations of African descent have suggested that human populations are uniform in their susceptibility to hypertension. ${ }^{28-31}$ This is in contrast with the hypothesis that people of African ancestry across the world may share a susceptibility to the adverse effects of environmental factors (in

Table 4 Comparison between the prevalence of reported hypertension and diabetes in non-attenders and attenders

\begin{tabular}{|c|c|c|c|c|c|c|}
\hline & \multicolumn{3}{|c|}{ Non-attenders } & \multicolumn{3}{|c|}{ Attenders } \\
\hline & $n$ & Total & $\%$ & $n$ & Total & $\%$ \\
\hline \multicolumn{7}{|l|}{ Hypertension } \\
\hline White people & 34 & 166 & 26 & 113 & 520 & 22 \\
\hline African descent & 32 & 118 & 37 & 251 & 548 & 46 \\
\hline South Asian origin & 12 & 54 & 29 & 122 & 504 & 24 \\
\hline \multicolumn{7}{|l|}{ Diabetes } \\
\hline White people & 4 & 165 & 2 & 12 & 524 & 2 \\
\hline African descent & 11 & 116 & 10 & 57 & 547 & 10 \\
\hline South Asian origin & 11 & 42 & 26 & 62 & 502 & 13 \\
\hline
\end{tabular}

particular high salt intake) on blood pressure. ${ }^{32}{ }^{33}$ We found no difference in hypertension between Caribbeans (first generation immigrants in the United Kingdom with a median duration of stay of 33 years) and West Africans (first generation of more recent immigration in the United Kingdom with a median duration of stay of 23 years). Given the similarity in their risk factor profile (with the exception of smoking rates), the notion that a raised risk is already present in their countries of origin ${ }^{34-36}$ and that it is unlikely that they have retained some common environmental exposures typical of their place of origin (very different in the Caribbean and in West Africa), our data are compatible with a potential interaction between environmental factors and underlying susceptibility shared by people of African ancestry. Further studies are necessary to establish the contributing role, if any, of the genetic background to the undisputed effects of environmental factors in the development of high blood pressure in this group.

South Asians also have a higher prevalence of hypertension than white people (though lower than people of African descent), similar to that now detectable in urban India. ${ }^{37}$ This has not always been emphasised in previous studies of ethnic groups in the United Kingdom ${ }^{16}$ and could explain the raised mortality from stroke experienced by South Asian people in England and Wales. ${ }^{1}$ The lack of awareness of the raised prevalence of hypertension among South Asians may also explain the lower detection rate for hypertension.

\section{DIABETES}

In excess of one in five people of South Asian origin had diabetes. This was true for men and women and was higher than in any other ethnic group. Coronary heart disease is the first cause of death in South Asians both in England and Wales $^{1}$ and in their country of origin. ${ }^{38}$ This risk may be mediated by hyperinsulinaemia and central adiposity, more common in South Asians. ${ }^{15} 1639$ Diabetes was also more prevalent in people of African descent. White people were less likely to have been diagnosed before the survey than the other ethnic groups. This suggests that the greater awareness of a higher prevalence of diabetes among ethnic minorities has led to a greater detection rate by primary care teams. Alternatively, it may be argued that the progression of diabetes could be accelerated in these ethnic minority groups, thus leading to more symptoms and to diagnosis. Although this may be true for the South Asians, ${ }^{39}$ it does not appear to be the case for those of African origin. ${ }^{40} 41$ It is surprising therefore that the treatment of diabetes was more common among people of African descent, although the diabetes does not appear to be more aggressive in this ethnic group. The findings of a higher proportion of undetected diabetics among the white people is intriguing because, although the prevalence of diabetes is low in this group, they represent the majority of the population, and hence they will produce the majority of cases of diabetes in the community. 
OBESITY

The Health of the Nation targets recognise that the reduction of obesity would play a major role in reducing the level of ill health and death caused by coronary heart disease and stroke. The targets were to reduce the prevalence of obesity from $8 \%$ in men and $12 \%$ in women in $1986 / 87$ to $6 \%$ in men and $8 \%$ in women by the year $2005 .^{5}$ The prevalence of severe obesity in white people was $15 \%$ in men and $19 \%$ in women, in line with other recent surveys that indicate an increase in the prevalence of obesity. ${ }^{6}$ The high prevalence of obesity in women of African descent, both from the Caribbean and from West Africa, may contribute to the higher prevalence of hypertension and diabetes and represents a major challenge for health promotion and preventive strategies.

RAISED SERUM CHOLESTEROL AND SMOKING Raised serum cholesterol and smoking were more common among the white people. Comparisons within ethnic groups revealed a significant difference in the smoking rates, low among both West African men and women as compared to Caribbeans, and low in South Asian women and in Hindu men compared to Muslim men. While serum cholesterol and smoking do not explain differences in vascular risk between ethnic groups, they remain important in explaining risk in individuals within ethnic groups. ${ }^{42} 43$

Differences in risk factor levels could be related to differences in diet between ethnic groups. The assessment of diet in ethnic groups requires the development and validation of dietary assessment methods ${ }^{44}{ }^{45}$ which are not fully available yet in the United Kingdom. Previous attempts to relate diet in ethnic groups to cardiovascular risk have been inconclusive. ${ }^{46}{ }^{47}$ The use of specific dietary biomarkers might prove useful in this regard. ${ }^{48}$

POTENTIAL LIMITATIONS

It is important to consider the biases that can arise in population based studies of ethnic minority groups. ${ }^{49}$ Bias could have resulted from selection of general practices, selection of subjects, or a low response rate. The selection of general practices is unlikely to have resulted in biased estimates of differences between ethnic groups. All types of general practitioner were represented (from fund holding to single handed) and subjects from each ethnic group were invited from each practice. Where quality of general practitioner care was relevant, as in the assessment of management and control of hypertension and diabetes, then analyses were adjusted for practice. The selection of subjects by surname could not have biased the sampling of South Asians and West Africans, nor could the white group be biased, given that they were randomly selected. Where a selection bias could have resulted was in the Caribbean group. However, the consistency of results, both within the study (similar prevalence in Caribbeans and West Africans and similar sex differences) and between studies (results consistent with similar studies in the United Kingdom), argue against the likelihood of a system- atic bias. Finally bias could have resulted from a differential response rate by ethnic group (for instance, leading to healthier subjects less likely to attend). This is impossible to rule out. Response rate by ethnicity was difficult to calculate because ethnicity could not be assigned to those not responding to our invitation. For the same reason, ethnicity was difficult to attribute to those names who were on the list but not living at the address at the time of the survey ( $26 \%$ of sample frame). The inaccuracy of the age and sex registers was likely to be due in part to the mobility of the population in the Wandsworth area, as well as to delay in updating lists. This possibility was supported by the analysis of the electoral register. However, we were able to characterise in some detail those who refused to take part $(18 \%$ of sample frame). This yielded a high response rate and indicated that this group was comparable to the population surveyed for all aspects we considered. Moreover, our findings have external validity. Where they can be compared they are in general agreement with other similar studies, ${ }^{9} 151719-22$ suggesting that any systematic bias is unlikely. These findings could therefore be applied to the local South London population from which they were drawn.

\section{CONCLUSIONS}

There are marked differences in the distribution of cardiovascular risk factors and their detection and management among different ethnic groups in Britain. They are amenable to prevention and effective treatment. In particular, the focus of future activities should concentrate on the improvement in the prevention, detection, and management of hypertension and diabetes, as well as of severe obesity in women of African descent. Preventive and treatment strategies developed and assessed in white populations may not apply to ethnic minorities. Strategies should be specifically developed, validated, and assessed to consider both cultural acceptability, which is likely to affect uptake and compliance, and underlying susceptibility, which may vary the effectiveness of preventive and treatment options in different ethnic groups. These actions will require the involvement of both primary care health professionals (prevention and detection) and secondary health care settings (appropriate investigation and management and adequate control).

We thank the participating general practitioners for their cooperation and help in allowing access to their registers and patients, the staff in the Blood Pressure Unit and in the Department of Public Health Sciences for their technical support, and Ross Anderson and Graham MacGregor for their encouragement and advice. We also thank C Chazot, S Choudhary, J Cox, E J Folkerd, R Iacone, D Powell, $M$ Rothwell, and N Valli for their hard work. The sources of funding were Wandsworth Health Authority, South West Thames Regional Health Authority, NHS R\&D Directorate, the British Heart Foundation, and the British Diabetic Association.

1 Balarajan R. Ethnic differences in mortality from ischaemic heart disease and cerebrovascular disease in England and Wales. BMF 1991;302:560-4.

2 Roderick PJ, Jones I, Raleigh VS, McGeown M, Mallick N. Population need for renal replacement therapy in Thames regions: ethnic dimension. BMF 1994;309:1111-4.

3 Raleigh VS. Diabetes and hypertension in Britain's ethnic minorities: implications for the future of renal services. BMF 1997;314:209-13. 
4 Epstein FH. Cardiovascular disease epidemiology. Circulation 1996;93:1755-64.

5 Secretary of State for Health. The Health of the Nation $(\mathrm{Cm}$ 1523), London: HMSO, 1991:1-112.

6 Colhoun H, Prescott-Clarke P, eds. Health survey for England 1994. London: HMSO, 1996.

7 Haskey J. The ethnic minority populations resident in private households: estimates by county and metropolitan district of England and Wales. Popul Trends 1991;63:22-35.

8 McKenzie K, Crowcroft NS. Ethnicity, race and culture: guidelines for research, audit and publication. $B M \mathcal{F}$ 1996;312:1094

9 McKeigue PM, Shah B, Marmot MG. Relation of central obesity and insulin resistance with high diabetes prevalence and cardiovascular risk in South Asians. Lancet 1991;337: $382-6$.

10 George CF, Lewis PJ, Petrie A. Clinical experience with use of ultrasound sphygmomanometer. Br Heart $\mathcal{F}$ 1975;37: $804-7$.

11 Technique of blood pressure measurement. 7 Hypertens 1985;3:293.

12 Subcommittee of WHO/ISH Mild Hypertension Liaison Committee. Summary of the World Health OrganisationInternational Society of Hypertension guidelines for the management of mild hypertension. $B M \mathcal{F} 1993 ; 307: 1541$ 6.

13 World Health Organisation Study Group on Diabetes Mellitus. Report. WHO Tech Rep Ser 1985; No 727.

14 Armitage P, Berry G. Statistical methods in medical research, 3rd ed. Oxford: Blackwell Scientific Publications, 1994.

15 Cruickshank JK, Beevers DG, Osbourne VL, Haynes RA, Corlett JC, Selby S. Heart attack, stroke, diabetes and hypertension in West Indians, Asians, and whites in Birmingham. BMF 1980;281:1108.

16 Cruickshank JK, Jackson SHD, Beevers DG, Bannan LT, Beevers M, Stewart VL. Similarity of blood pressure in blacks, whites and Asians in England: the Birmingham factory study. F Hypertens 1985;3:365-71.

17 Forrest RD, Jackson CA, Yudkin JS. Glucose intolerance and hypertension in North London: the Islington Diabetes and hypertension in North London:
Survey. Diabet Med 1986;3:338-42.

18 McKeigue PM, Marmot MG, Syndercombe Court YD, Cottier DE, Rahman S, Riemersma RA. Diabetes, hyperinsulinaemia, and coronary risk factors in Bangladeshis in East London. Br Heart $\mathcal{F}$ 1988;60:390-6.

19 Cruickshank JK, Cooper J, Burnett M, MacDuff J, Drubra U. Ethnic differences in fasting plasma C-peptide and insulin in relation to glucose tolerance and blood pressure. Lancet 1991;338:842-7.

20 Simmons D, Williams DRR, Powell MJ. The Coventry Diabetes Study: prevalence of diabetes and impaired glucose tolerance in Europids and Asians. $O \quad \mathcal{H} \mathrm{Med}$ 1991;296:1021-30.

21 Simmons D, Williams DRR, Powell MJ. Prevalence of diabetes in different regional and religious South Asian communities in Coventry. Diabet Med 1992;9:428-31.

22 Chaturvedi N, McKeigue PM, Marmot MG. Resting and ambulatory blood pressure differences in Afro-Caribbeans ambulatory blood pressure differences in Af.

23 Smith WCS, Lee AJ, Crombie IK, Tunstall-Pedoe H. Control of blood pressure in Scotland: the rule of halves. $B M \mathcal{F}$ trol of blood pressur

24 Cruickshank JK, Riste L, Amica C, Griffiths S, Savage J, Greaves E, et al. Rule of halves in hypertension control: how efforts in primary care can produce better results in black than in white population samples [abstract]. $\mathcal{F}$ Hyperten 1994;12:1315.

25 Colhoun HM, Dong W, Poulter NR. Hypertension management: is England sticking to the rule of halves? Results from the health survey for England 1994 [abstract]. F Hypertens 1996;14(suppl 1):289.

26 Hart JT. Hypertension: community control of high blood pressure, 3rd ed. Oxford: Radcliffe Medical Press, 1993.

27 Du K, Cruickshank K, McNamee R, Saraee M, Sourbutts J, Summers A, et al. Case-control study of stroke and the quality of hypertension control in north west England. quality of hypertension

28 Kaufman JS, Owoaje EE, James SA, Rotimi CN, Cooper RS. Determinants of hypertension in West Africa: contribution of anthropometric and dietary factors to urbanrural and socioeconomic gradients. Am $\mathcal{f}$ Epidemiol 1996;143:1203-18.
29 Kaufman JS, Durazo-Arvizu RA, Rotimi CN, McGee DL, Cooper RS. Obesity and hypertension prevalence in populations of African origin. Epidemiology 1996;7:398-405.

30 Kaufman JS, Rotimi CN, Brieger WR, Oladokun MA, Kadiri S, Osotimehin BO, et al. The mortality risk associated with hypertension: preliminary results of a prospective study in rural Nigeria. F Hum Hypertens 1996;10: $461-4$.

31 Cooper R, Rotimi C, Ataman S, McGee D, Osotimehin B, Kadiri $\mathrm{S}$, et al. The prevalence of hypertension in seven populations of West African origin. Am 7 Public Health 1997;87:160-8

32 Wilson TW, Grim CE. Biohistory of slavery and blood pressure differences in blacks today. A hypothesis. Hypertension 1991;17(suppl I):I122-8.

33 Moskowitz DW. Hypertension, thermotolerance and the "African gene": an hypothesis. Clin Exp Hypertens 1996;18 $1-19$.

34 Cruickshank JK, Alleyne SA. Black West Indian and matched white diabetics in Britain compared with diabetics in Jamaica: body mass, blood pressure and vascular disease. Diabetes Care 1987;10:170-9.

35 Miller GJ, Kirkwood BR, Beckles GLA, Alexis SD, Carson DC, Byam NTA. Adult male all-cause, cardiovascular and cerebrovascular mortality in relation to ethnic group, systolic blood pressure and blood glucose concentration in Trinidad, West Indies. Int F Epidemiol 1988;17:62-9.

36 Fang J, Madhavan S, Alderman MH. The association between birthplace and mortality from cardiovascular cetween birthplace and mortality from cardiovascular N Engl f Med 1996;335:1545-51.

37 Gupta R, Al-Odat NA, Gupta VP. Hypertension epidemiology in India: meta-analysis of 50 year prevalence rates and blood pressure trends. F Hum Hypertens 1996;10:465-72.

38 McKeigue PM, Miller GJ, Marmot MG. Coronary heart disease in South Asians overseas: an overview. F Clin Epidemiol 1989;42:597-609.

39 McKeigue PM, Ferrie JE, Pierpoint T, Marmot MG. Association of early-onset coronary heart disease in South Asian men with glucose intolerance and hyperinsulinemia. Circulation 1993;87:152-61.

40 Chaturvedi N, Fuller JH. Ethnic differences in mortality from cardiovascular disease in the UK: do they persist in people with diabetes? $\mathcal{F}$ Epidemiol Community Health 1996; 50:137-9.

41 Chaturvedi N, Jarrett J, Morrish N, Keen H, Fuller JH. Differences in mortality and morbidity in African Caribbean and European people with non-insulin dependent diabetes mellitus: results of 20 year follow up of a London cohort of a multinational study. BMF 1996;313:848-52.

42 Silman A, Loysen E, de Graaf W, Sramek M. High dietary fat intake and cigarette smoking as risk factors for ischaemic heart disease in Bangladeshi male immigrants in east London. F Epidemiol Community Health 1985;39:197209.

43 Miller GJ, Beckles GLA, Maude GH, Carson DC, Price SGL. High density lipoprotein cholesterol concentration as a predictor of coronary heart disease in West Indian men. $\mathcal{F}$ Epidemiol Community Health 1990;44:136-8.

44 Hankin JH, Wilkens LR. Development and validation of dietary assessment methods for culturally diverse populations. Am $\mathcal{F}$ Clin Nutr 1994;59(suppl):198-200S.

45 Sharma S, Cade J, Jackson M, Mbanya JC, Chungong S, Forrester $\mathrm{T}$, et al. Development of food frequency questionnaires in three population samples of African origin from Cameroon, Jamaica and Caribbean migrants to the UK. Eur f Clin Nutr 1996;50:479-86.

46 McKeigue PM, Marmot M, Adelstein AM, Hunt SP, Shipley MJ, Butler SM, et al. Diet and risk factors for coronary heart disease in Asians in Northwest London. Lancet 1985; ii: $1086-90$.

47 Sevak L, McKeigue PM, Marmot MG. Relationship of hyperinsulinemia to dietary intake in South Asian and European men. Am f Clin Nutr 1994;59:1069-74.

48 Ness AR, Cappuccio FP, Atkinson RW, Khaw KT, Cook DG. Plasma vitamin C in people of African descent, South Asian origin and Caucasians [abstract]. Can $\mathcal{f}$ Cardiol 1997;13(suppl B): 277B

49 Chaturvedi N, McKeigue PM. Methods for epidemiological surveys of ethnic minority groups. F Epidemiol Community Health 1994;48:107-11. 